\title{
ACTIVE MICROSTRIP ANTENNAS AND ANTENNA ARRAYS WITH FIELD-EFFECT TRANSISTORS
}

\author{
Vladimir E. Lyubchenko, Eugeny O. Yunevich, Valery I. Kalinin, Viktor D. Kotov, \\ Dmitry E. Radchenko, Sergey A. Telegin
}

Kotel'nikov Institute of Radio Engineering and Electronics, Branch in Fryazino, Russian Academy of Science, http:/ / fire.relarn.ru

141120 Fryazino, Moscow region, Russian Federation

lyubch@ire216.msk.su, yunevich@ms.ire.rssi.ru, val.kalinin@mail.ru, vdkotov@mail.ru, dm.radchenko@ gmail.com, telegins@bk.ru

Received 25.02.2015

\begin{abstract}
This paper summarizes the results of investigations, conducted by authors on the so called "active microwave antennas" - the structures, in which microstrip antenna is connected with active semiconductor element without intermediate feeder. The most attention is focused to the processes of microwave generation, particularly in the active antenna array. Active antenna, in this case antenna-oscillator (AO), looks as a planar log-periodic antenna, integrated with field-effect transistor at the dielectric substrate with metalized back side. Output microwave power of single AO was 5-7 $\mathrm{mW}$ at the frequency near $20 \mathrm{GHz}$ with efficiency up to $20 \%$. The opportunity of spatial power combining was studied for the linear and two-dimension arrays. It was shown, that during the operation of two AOs with frequency difference less than $50 \mathrm{MHz}$ mutual synchronization takes place, mostly due to the surface wave excitation in the dielectric substrate. Meanwhile for the effective power combining in two-dimensional array of 4 or more elements external signal source is necessary or special reflector can be used. Computer modeling and experimental study have shown that depending on the dielectric substrate thickness generation of monochromatic, multifrequency or chaotic signals is possible with output both to the free space and to the waveguide structures.
\end{abstract}

Keywords: antenna-oscillator, field-effect transistor, array of generators, synchronization, power combining.

PACS: 84.40.Ba

Bibliography -19 references

RENSIT, 2015, 7(1):3-14

DOI: $10.17725 /$ rensit.2015.07.003

Contents

1. INTRODUCTION (3)

2. Antenna-oscillator Design (4)

3. SYNCHRONIZATION AND POWER COMBINING (5)

4. Synchronization AND AOs power COMBINING IN THE OPEN CAVITY (8)

5. Multi-FreQuenCy genERATion IN THE AO (10)

5.1. Harmonics generation (10)

5.2. Chaotic generation (10)

6. MicrostriP ANTENNA-OSCILLATOR WITH SUBSTRATE INTEGRATED WAVEGUIDE OUTPUT (11)

6.1 DESIGN OF THE ANTENNA-OSCILLATOR, INTEGRATED WITH SIW (11)

6.2SIMULATION OF THE FIELD DISTRIBUTION
IN THE STRUCTURE (12)

7. Conclusions (12)

REFERENCES (12)

\section{INTRODUCTION}

Semiconductor devices being important part of modern microwave receiver and transmitter systems as active elements are characterized by high reliability, wide operation temperature range and possibility of application in the monolithic and hybrid integrated circuits. The main problem of the semiconductor devices is their output power, 
which dramatically decreases with increasing of the operation frequency [1]. This problem can be solved by means of power combing of the multiple power sources, in particular the microwave oscillators, performed as a microstrip antenna, integrated with semiconductor active device, so called antenna-oscillator (AO). It is stimulated by the fact, that antenna sizes decrease with increasing of the operation frequency and it becomes possible to place the twodimensional phased array of AOs on the common dielectric substrate.

Design problems of the microstrip AOs, integrated with semiconductor devices, and AOs arrays are considered in the number of papers and reviews [2-6]. The main efforts were focused on the interaction between antenna-oscillators for the most effective power combining [4]. The simplest way to realize AO is to use Gunn or IMPATT diodes, which are two-terminal devices and at the same time the self-oscillators, so antenna is used only as a load [7]. If the transistor is used as an active device, it is necessary to provide a feedback for the excitation of microwave oscillations. The scheme becomes more complicated, but the operation frequency range and power efficiency can be increased.

In this paper the results of microwave generation and power combining are demonstrated for the microstrip active integrated antennas with field-effect transistors, including the opportunities of their operation in the multi-element arrays as microwave power sources.

\section{ANTENNA-OSCILLATOR DESIGN}

The antenna-oscillator consists of the logperiodic microstrip antenna with fieldeffect transistor (FET), located on the

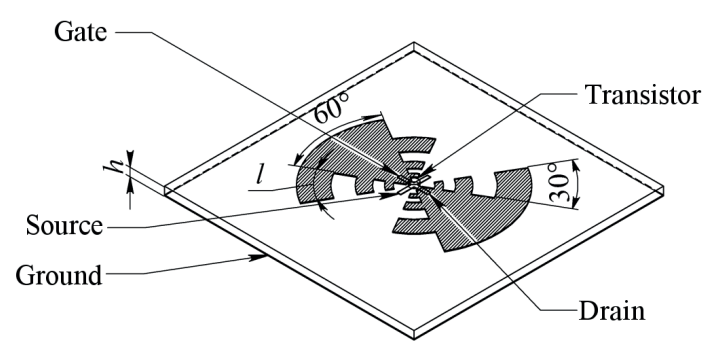

Fig. 1. Log-periodic antenna with the FET: $b$ - dielectric thickeness; 1 - length of the first antenna tooth.

dielectric substrate (Fig. 1). The "source" terminal of the transistor is connected to the metallized substrate back side through the vias.

The advantage of log-periodic type antennas is the wide operation frequency band, that allows to realize generation both in the single-frequency and multifrequency modes. Presence of the metal at the substrate back side turns the antenna into the oscillatory contours with a high Q-factor. So far both the analytical theory of the log-periodic antennas [8], and numerical modeling [9] are developed. The distance between the antenna plane and metallization of the back side plays an important role. The most effective generation is observed for $h$ close to the quarter of wavelength in the dielectric (Fig. 2).

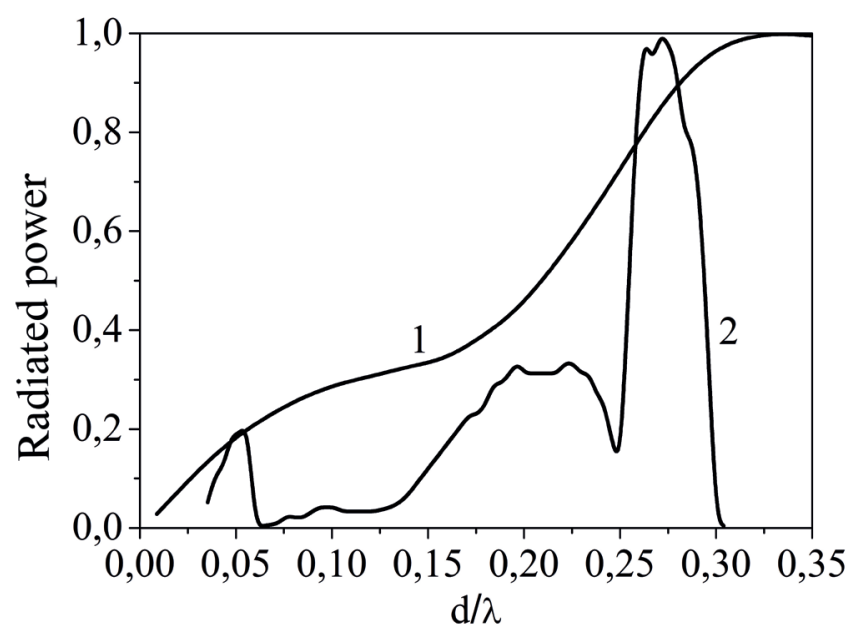

Fig. 2. Dependence of the radiated power on the substrate thickness: 1 - calculation; 2 - experiment. 
Oscillations usually arise at the frequency determined by the first, longest tooth: $f_{1}=c\left(4 l \sqrt{\frac{\varepsilon_{d}+1}{2}}\right)^{-1}$, where $l$ is the tooth length, $\varepsilon_{\mathrm{d}}-$ dielectric permeability of the substrate [8]. Furthermore, if the transistor gain is enough, higher frequency oscillations corresponding to shorter teeth may occur at $f_{n}=f_{1}(\sqrt{2})^{n-1}$, where $n$ is a tooth number. The oscillation spectrum at frequency corresponding to the length of the first antenna tooth is presented at Fig. 3. As one can see, the observed oscillation frequency (13.68 $\mathrm{GHz})$, corresponds to the calculated value (13.8 $\mathrm{GH}$ ₹).

Mostly the packaged FETs with operating frequency of 20-25 $\mathrm{GHz}$ were used as active elements. Observed oscillation power was 5-7 $m W$ with the efficiency up to $20 \%$.

\section{SYNCHRONIZATION AND POWER COMBINING}

Interest to the semiconductor $\mathrm{AOs}$, as it was noted above, is considerably stimulated with possibility of their coupling in the multi-element arrays, allowing to realize the spatial power combining. For this purpose it is necessary to provide frequency and phase synchronization of the antenna-oscillators array, located at the common dielectric

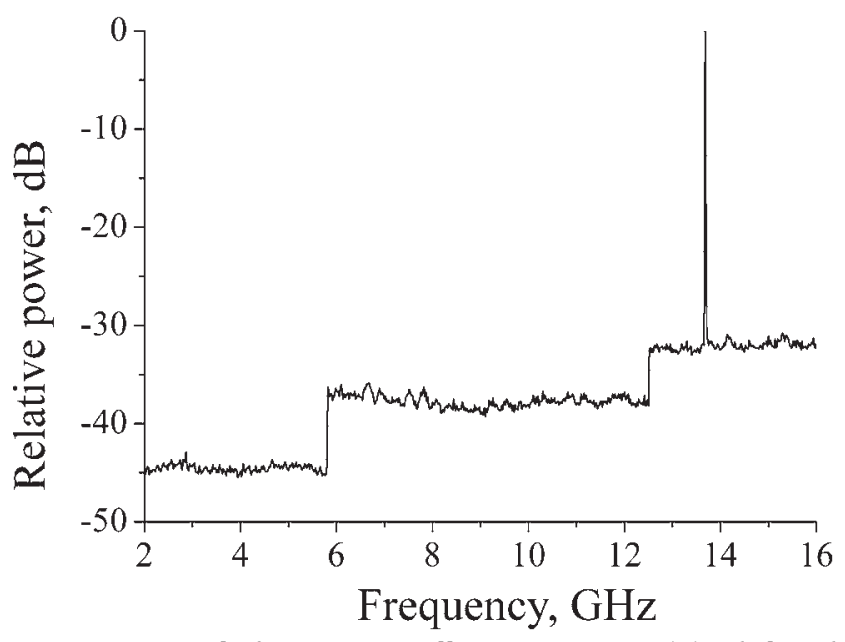

Fig. 3. A single-frequency oscillation spectrum. Tooth length $l=3.95 \mathrm{~mm}, d=2 \mathrm{~mm}(0.15 \lambda)$.

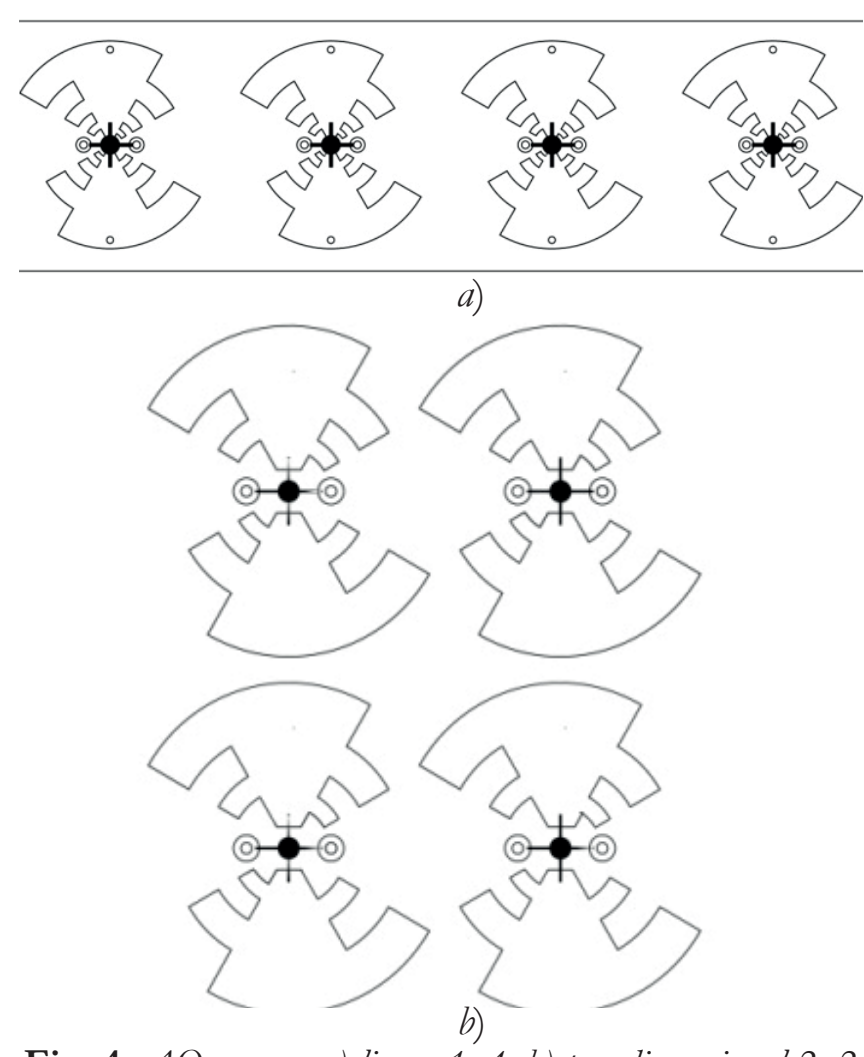

Fig. 4. $A O$ arrays; a) linear 1x4; b) two-dimensional $2 \times 2$. substrate. In this study two types of arrays linear and two-dimensional were investigated (Fig. 4).

Our experiments have proved that during the operation of two AOs with oscillation frequency difference less than $50 \mathrm{MHz}$. their mutual synchronization occurs. The synchronization can take place at bigger frequency dispersion if the quantity of $\mathrm{AO}$ in the array increases (Fig. 5).

As a result oscillation and radiation of the array is realized at a single frequency. Mutual coupling of the oscillators is carried out mostly by excitation of the surface waves in the dielectric substrate. The mutual synchronization bandwidth decreases dramatically when mutual coupling of AOs through the substrate decreases. If antennas are located linearly on the common substrate (a one-dimensional array) and the distance between centers of the adjacent antennas is close to the wavelength in dielectric, mutual synchronization and power combining 


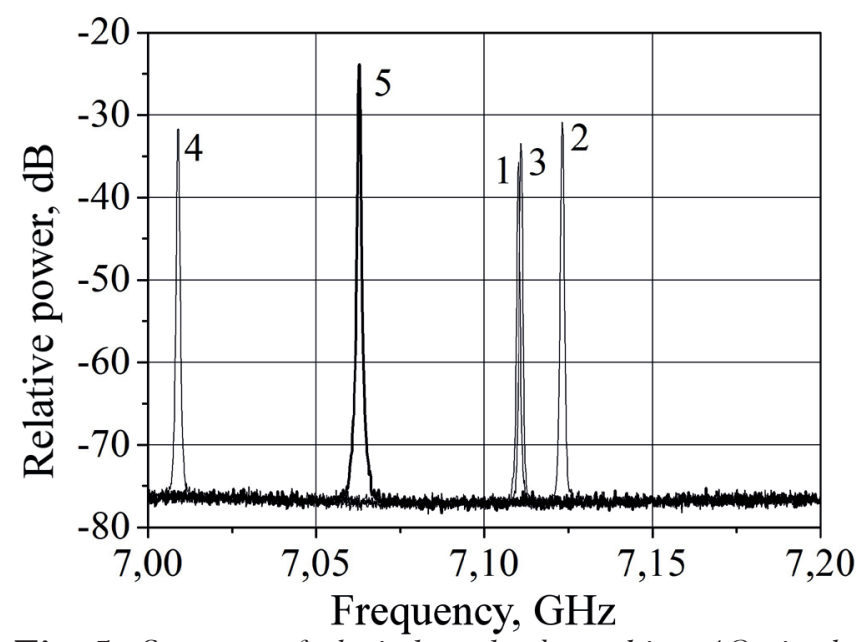

Fig. 5. Spectrum of the independently working $A O s$ in the $2 \times 2$ array (1-4); resulting spectrum of mutually synchronized array (5).

of three and more oscillators occurs. This is confirmed by narrowing of the total radiation pattern. However in the case of two-dimensional antenna array, despite the existence of frequency synchronization, phase synchronization is not realized, and the wide or even multi-beam radiation pattern is formed (Fig. 6).

It is possible to realize the frequency and phase synchronization for a couple of independent oscillators by irradiation the array with an external signal. To investigate this opportunity the setup presented at Fig. 7 was used.

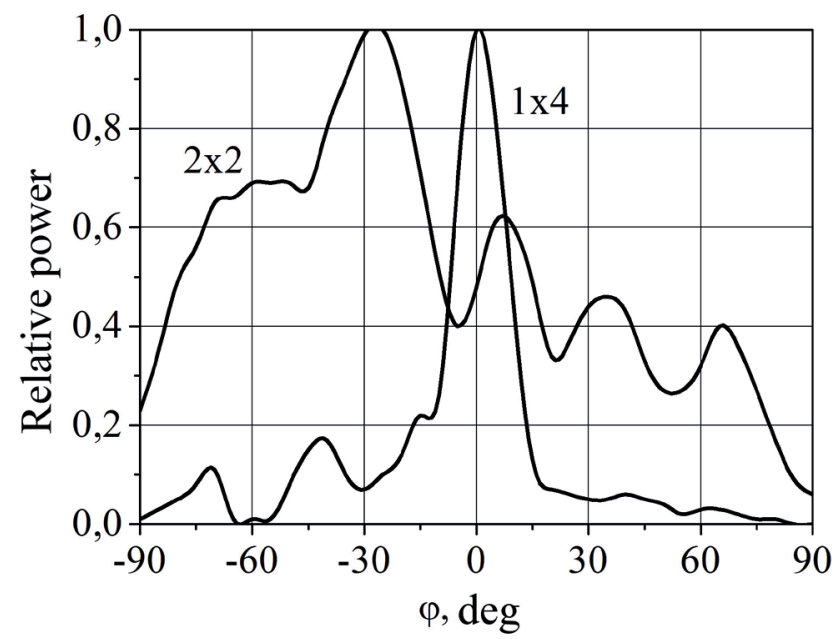

Fig. 6. Radiation patterns of the mutually synchronized $2 \times 2$ and $1 \times 4$ arrays.

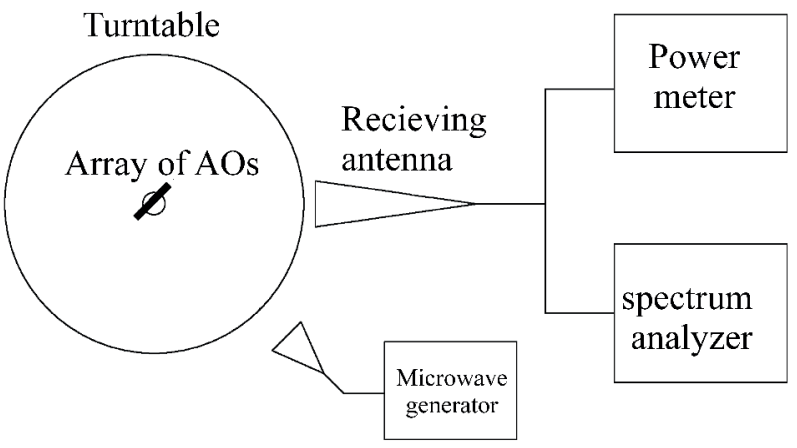

Fig. 7. Measurement setup for the $A O$ radiation pattern investigation.

Under the influence of external locking signal the oscillation frequency of single $\mathrm{AO}$ can be tuned in the frequency range up to $400 \mathrm{MHz}[10,11]$. The radiation power that is necessary for the synchronization is more than 10 times less than the power generated by $\mathrm{AO}$.

Possibility of external injection locking both mutual synchronized and independently operating $\mathrm{AOs}$ was investigated. In the case of mutually synchronized AOs, the frequency range in which synchronization at the frequency of an external signal takes place, depends on the number of $\mathrm{AOs}$ and the power flow density of the external signal (Fig. 8). One

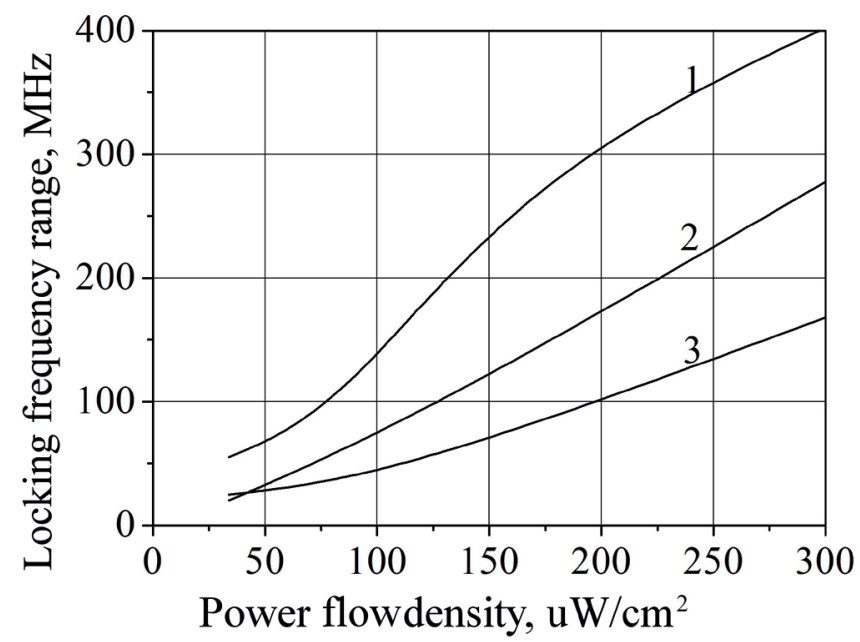

Fig. 8. Dependence of locking frequency range on the external locking signal power flow density for separated $A O$ (1) and linear arrays of two (2) and three (3) mutually synchronized AOs. 
can see from the fig. 8 that with increasing of the number of operating oscillators the locking range of external signal decreases and monotonously grows as the external power flow increases.

In the case of simultaneous $\mathrm{AO}$ operation in the array and without mutual synchronization, the possibility of external injection locking depends on many factors: number of AOs, detuning of their oscillation frequencies and power of oscillation, arranging of antennas, external signal power flow density [12]. For example, in the linear array of two AOs external locking by the field with 300 $\mathrm{uW} / \mathrm{cm}^{2}$ power flow is observed when the self-oscillating frequency dispersion does not exceed $150 \mathrm{MHz}$ (near the frequency of $16.5 \mathrm{GHz}$ ). It considerably exceeds admissible detuning of frequencies when mutual synchronization takes place.

Evolution of linear array radiation spectrum under the external signal injection is presented in Fig. 9. In the case given in Fig. 9a self-frequencies of three $\mathrm{AO}$ are located in the range of 250 $M H_{z}$ and in the lack of an external signal, due to coupling between oscillators, the asynchronous mode with multi-frequency oscillation spectrum is established. When the external signal is out of the locking range the mutual synchronization is observed (Fig. 9b) and all antennas oscillate at the common frequency out of the frequency of external locking signal. The resulting radiation spectrum contains the common oscillation frequency (1), frequency of the injection signal (2) and combinational components. After tuning and entry of the injection signal into the locking range $(\sim 150 \mathrm{MH} \approx)$ full synchronization of all

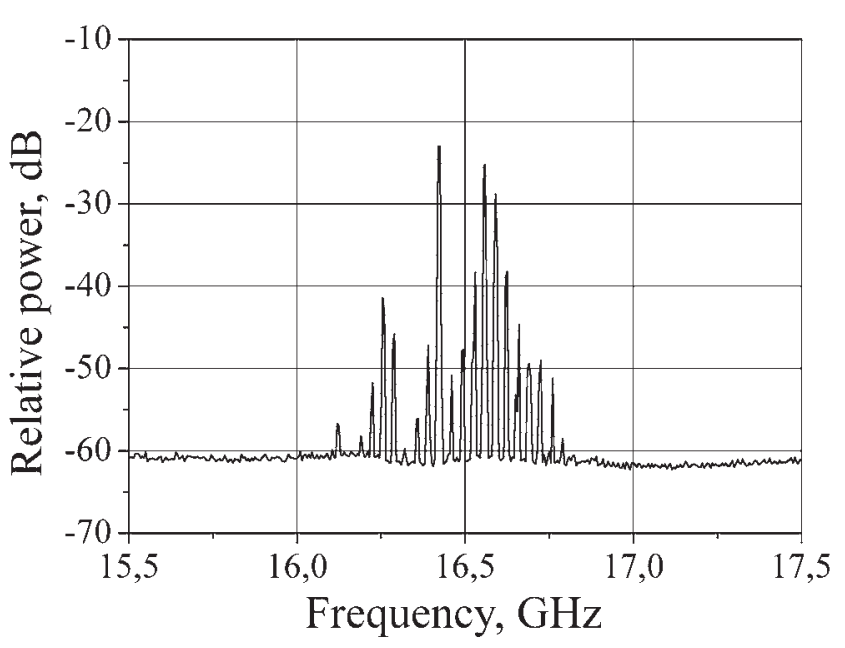

a)

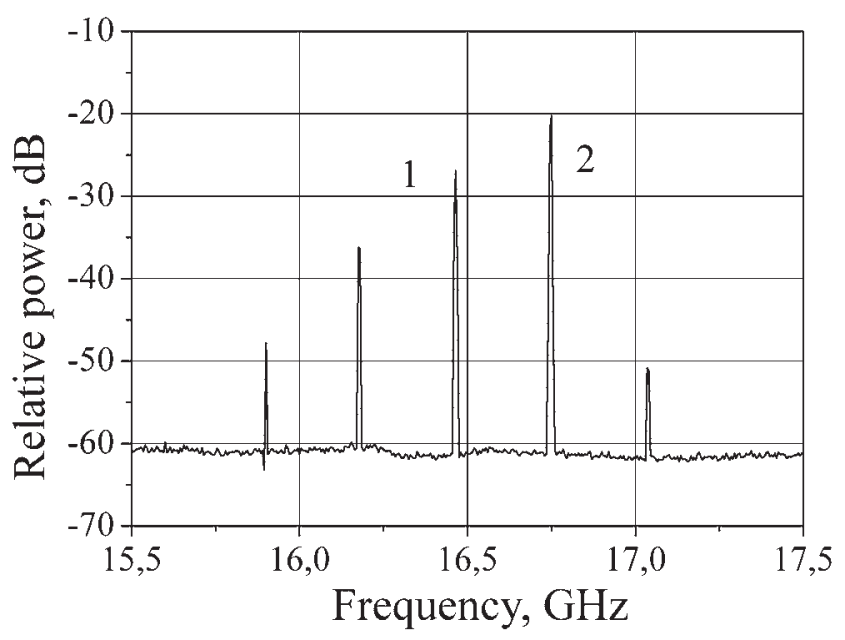

b)

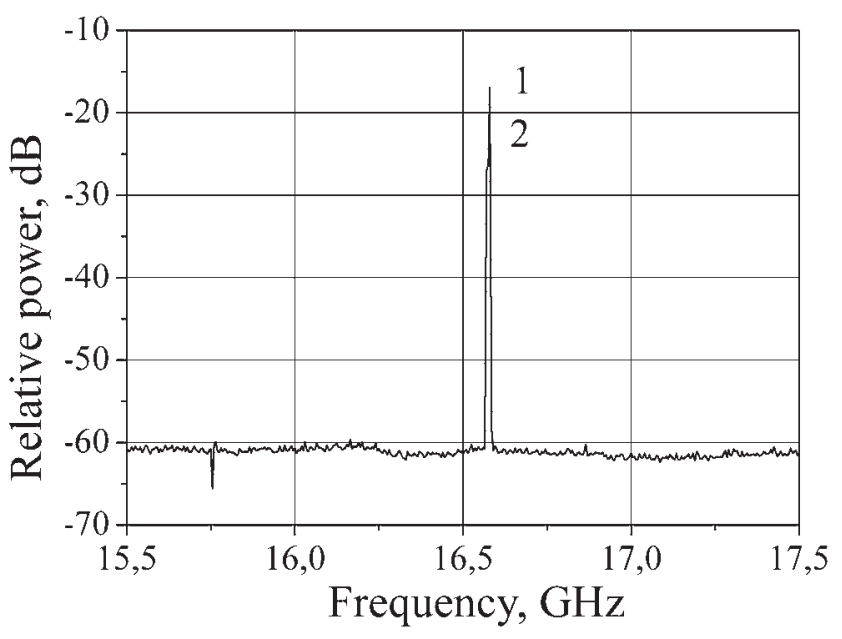

c)

Fig. 9. Evolution of 3-element array radiation spectrum under the external synchronization: 1 - $A O$ radiation frequency, 2 - external signal frequency. 


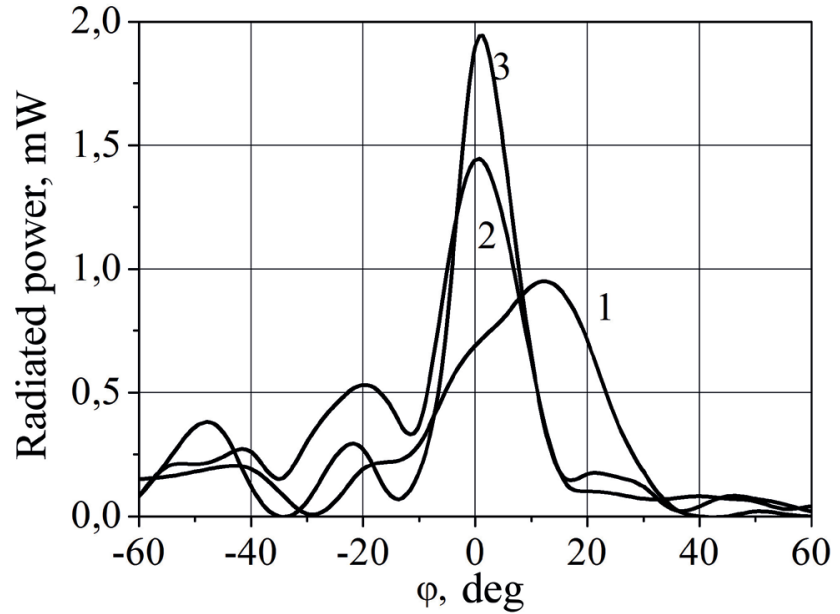

Fig. 10. Radiation patterns of the array: 1 - AOs are not synchronized; 2 - mutual synchronization; 3 - external synchronization.

AO array at the injection signal frequency (Fig. 9c) is observed.

At the Fig. 10 radiation patterns of 4-element array for various cases of synchronization are shown.

Radiation pattern width at $-3 d B$ level $(\varphi)$, peak radiation power in the maximum of radiation pattern $\left(P_{m}\right)$ and the total radiation power $\left(P_{0}\right)$ were measured. The results of radiation parameter measurement are shown in the Table 1.

$$
P_{0}=P_{m}\left(\frac{4 \pi R}{\lambda_{0}}\right)^{2} \frac{1}{G_{a} G_{h}},
$$

where $G_{a}$ and $G_{b}$ are coefficients of the antenna directivity and receiving horn antenna respectively; $R$ is a distance between $A O$ and the receiving antenna. Antenna directivity was calculated from the width of the main lobe at the $-3 d B$ level in two planes passing through the array axis. Radiation patterns Table 1. Antenna array radiation parameters in the various modes of synchronization

\begin{tabular}{|l|c|c|c|}
\hline Radiation parameter & $\varphi, \mathrm{deg}$ & $P_{m}, \mathrm{~mW}$ & $P_{0}, \mathrm{~mW}$ \\
\hline Single AO & 65 & 0.17 & 7 \\
\hline Array without locking & 30 & 0.93 & 14.9 \\
\hline $\begin{array}{l}\text { Mutual synchronization } \\
\text { of the array }\end{array}$ & 17 & 1.44 & 13.7 \\
\hline $\begin{array}{l}\text { External injection locking } \\
\text { of the array }\end{array}$ & 13 & 1.9 & 14 \\
\hline
\end{tabular}

were measured in the plane passing through the array axis. Radiation pattern width in the orthogonal plane is equal to the width of the single antenna pattern.

One can see from the data in Fig. 10 and Table 1 that in the linear array partial narrowing of the radiation pattern can take place even in the absence of synchronization due to asynchronous interaction between AOs. However the radiation pattern is quite wide and its maximum shifts from the normal. Mutual synchronization allows to realize the power combining, and radiation pattern width narrows four times compared to the independently operating AO. Presence of locking signal leads to additional narrowing of the radiation pattern and growth of the radiated power in the maximum. It can be related with change of the radiation pattern form for every single antenna-oscillator under the influence of synchronizing radiation. Radiation pattern of the single antenna under the influence of synchronizing radiation signal is shown in Fig. 11. Considerable change of the radiation pattern form can be caused by change of the regime of transistor operation and/or the impedance of antenna.

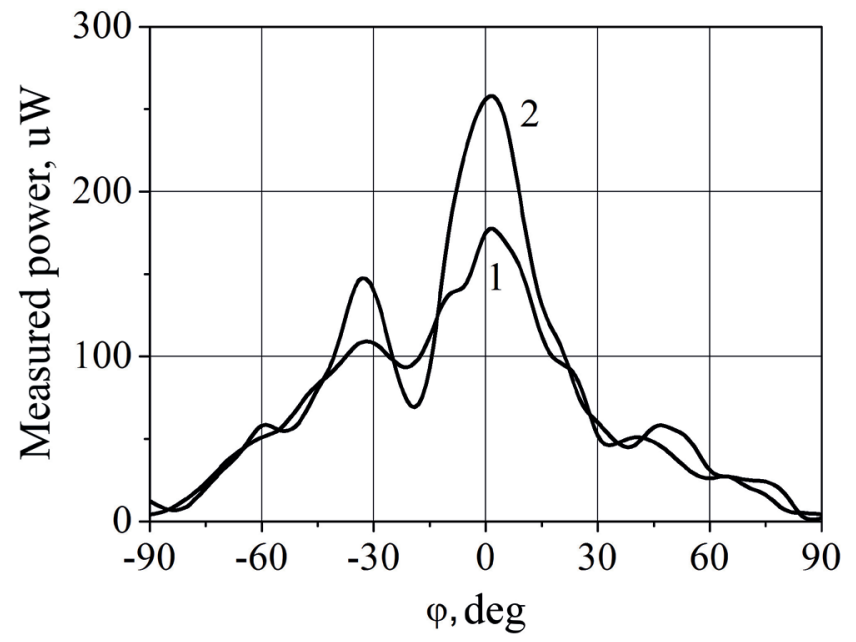

Fig. 11. Radiation pattern of single AO without external injection (1) and synchronized by an external field (2). 


\section{SYNCHRONIZATION AND AOS POWER COMBINING IN THE OPEN CAVITY}

Using of the external injection locking is connected with considerable complication of the set up since it needs the external source of locking signal. Meanwhile placing of the semitransparent dielectric mirror over the antenna array (Fig. 12), results in increasing of AOs coupling and their mutual synchronization. Spatial power combining can be improved under the impact of the signal reflected from the mirror, as like as it was noted in [13]. In this case discrepancy of the AO oscillation self-frequencies can reach $150 \mathrm{MHz}$, that in the absence of mirror is possible only at the considerable power from the external locking signal source.

Investigation of the AOs with semitransparent dielectric plate shows that presence of the reflecting mirror considerably changes the radiation pattern (Fig. 13) and maximum of the peak power is observed at the distance between antenna and mirror equal to $0.5 \lambda$. In some cases also the significant increasing of total oscillation power is observed, and efficiency may reach $30 \%$.

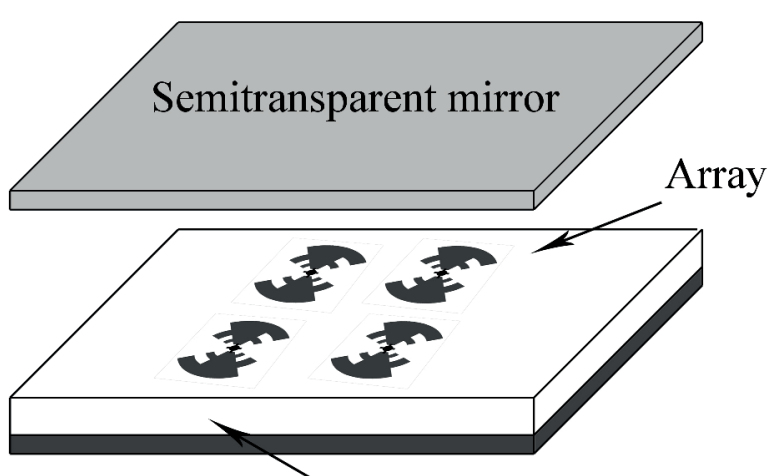

Dielectric substrate

Fig. 12. Placement of the $A O$ array in the open resonator with polycore semitransparent mirror $(\varepsilon r=9.7$; reflection coefficient $=0.26$ )

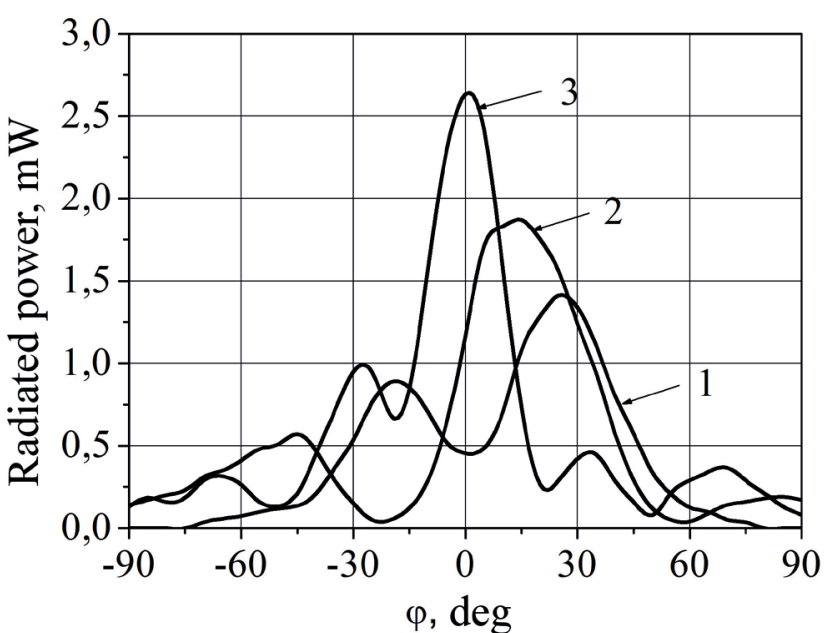

Fig. 13. Radiation patterns of $2 \times 2$ array under the conditions of synchronization and power combining in the open resonator. 1 - no synchronization; 2 - mutual synchronization (discrepancy of self-frequencies of $A O s \Delta f \leq 50 \mathrm{MH}$ z); 3 - in the open cavity with dielectric mirror $(\Delta f \leq 150 \mathrm{MH}$; )

To understand the reasons of the considerable change of the radiation pattern the model calculation of electric energy
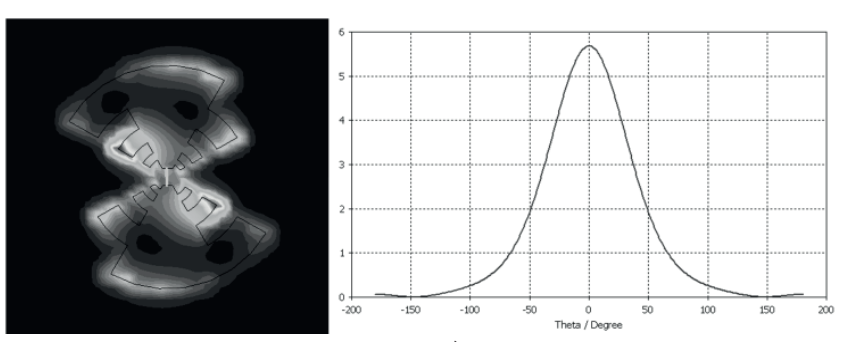

a)
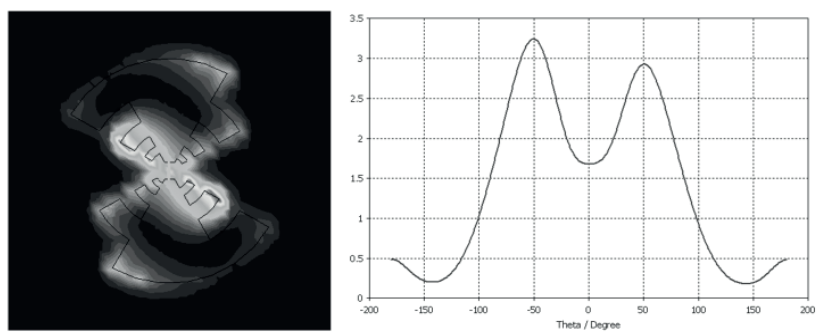

b)
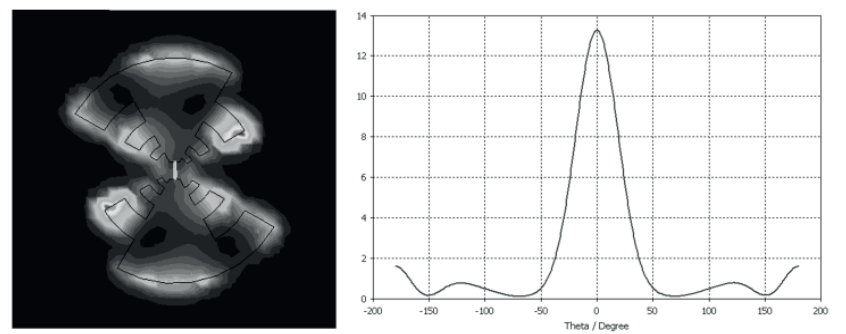

c)

Fig. 14. Evolution of the electric energy density distribution in the plane of antenna and radiation: a) no mirror; b) mirror at the distance $0,2 \lambda ; c)$ mirror at the distance $0,5 \lambda$. 
density distribution in the log-periodic antenna plane was performed (Fig. 14).

Change of the reflecting mirror location leads to change of the radiated energy distribution in the antenna plane and, therefore, to change in the radiation pattern.

\section{MULTI-FREQUENCY \\ GENERATION IN THE AO}

There is a possibility of harmonic oscillations in the $\mathrm{AO}$, based on the log-periodic antenna, due to the presence of multiple oscillator circuits. Typical picture is shown at Fig. 15. The possibility and characteristics of the oscillations depend on the transistor gain and its frequency dependence.

\subsection{HIGH HARMONIC GENERATION}

In order to obtain millimeter wave oscillations the non-packaged transistor $(6 \mathrm{~dB}$ gain at $40 \mathrm{GHz}$ ) and open microwave cavity were used. In this case, the radiation was carried out through the hole in the center of the spherical mirror. Without cavity there were no oscillations at the first harmonic, because of too small transistor gain. Otherwise, oscillations at the first and second harmonic frequencies were observed when the open cavity was used (Table 2).

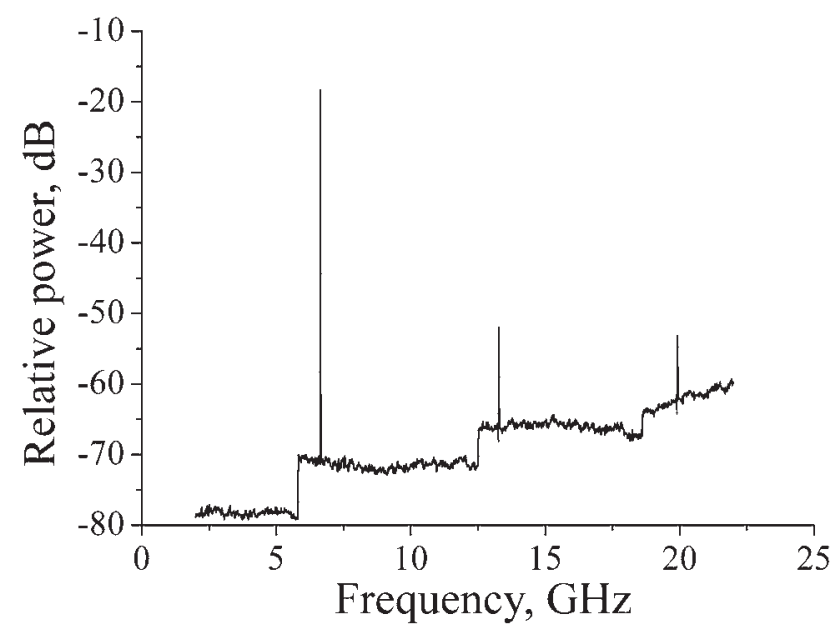

Fig. 15. Multi-frequency oscillations in $A O$.
Table 2.

Oscillation power on the first (I) and second (II) harmonic

\begin{tabular}{|c|c|c|c|c|c|c|}
\hline \multirow{2}{*}{ Sample } & \multicolumn{2}{|c|}{$\begin{array}{c}\text { Calculated frequency, } \\
\text { GHz }\end{array}$} & \multicolumn{2}{c|}{$\begin{array}{c}\text { Measured frequency, } \\
\text { GHz }\end{array}$} & \multicolumn{2}{c|}{ Measured power, mW } \\
\cline { 2 - 7 } & I harm. & II harm & I harm. & II harm. & I harm. & II harm. \\
\hline 1 & 22 & 44 & 22 & 42 & 0.8 & 0.14 \\
\hline 2 & 32 & 64 & 36 & 58 & 1 & 0.1 \\
\hline
\end{tabular}

Possibility of the second harmonic generation is of practical interest when there is no way to obtain oscillations at the desirable frequency in the first harmonic regime because of too small transistor gain [14].

\subsection{CHAOS GENERATION}

Some essential features of the AO's spectrum appears at small substrate thicknesses (0.10.03) $\lambda$. In [15] it is mentioned that for a significant shift from the quarter wavelength thickness of the substrate $\mathrm{AO}$ generation becomes unstable. Several samples with

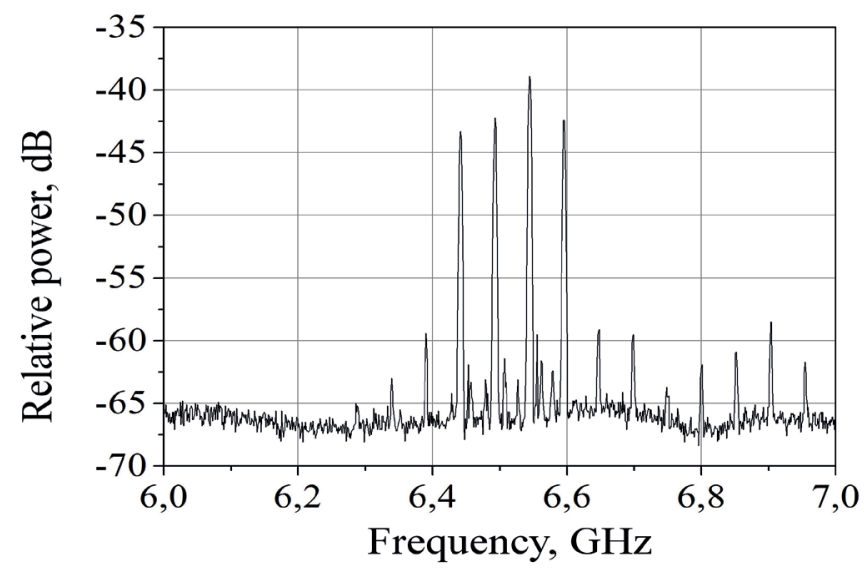

a)

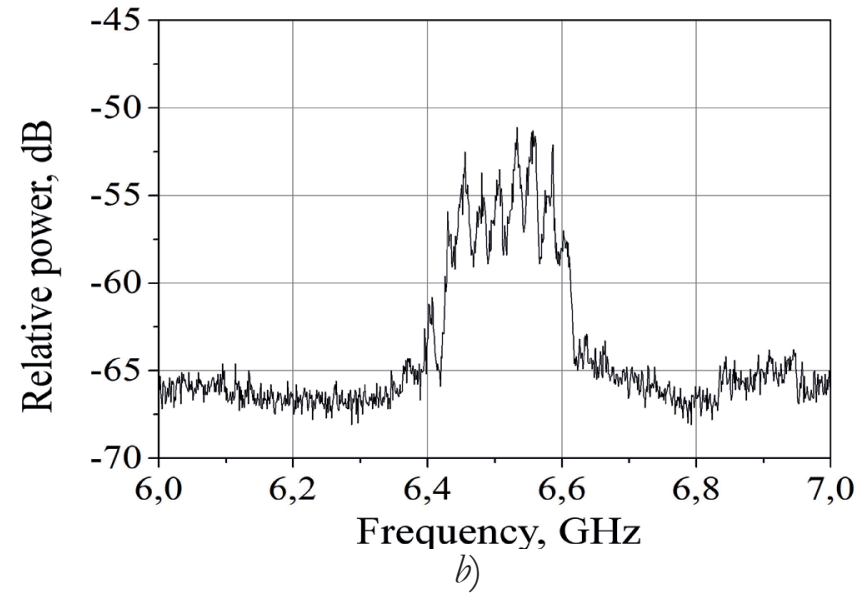

Fig. 16. Switching from multi-frequency (a) to chaotic (b) generation. 
different dimensions were fabricated to study the effect of switching to unstable generation. Stable single frequency generation was observed at thicknesses of $(0.15-0.25) \lambda$. At smaller substrate thickness $(0.06 \lambda)$ single frequency generation was absent but the chaotic one was observed (Fig. 16).

Multi-frequency generation with discrepancy $50 \mathrm{MHz}$ between spectral lines was observed. With small changes in the transistor bias voltages one can switch generation to the chaotic regime.

Bandwidth of the chaotic generation was about $200 \mathrm{MHz}$ (about $3 \%$ of the center frequency). The signal is not really chaotic, so it's autocorrelation function has some side spikes (Fig. 17).

\section{MICROSTIP ANTENNA- OSCILLATOR WITH SUBSTRATE INTEGRATED WAVEGUIDE OUTPUT}

So far, we have mostly considered the output radiation in the open space. However, for many applications it is necessary to direct the output radiation into the waveguides for processing. The feasible design for the integration with antenna-oscillator is the substrate integrated waveguide (SIW).

Substrate integrated waveguide is a transmission line, which consists of the dielectric

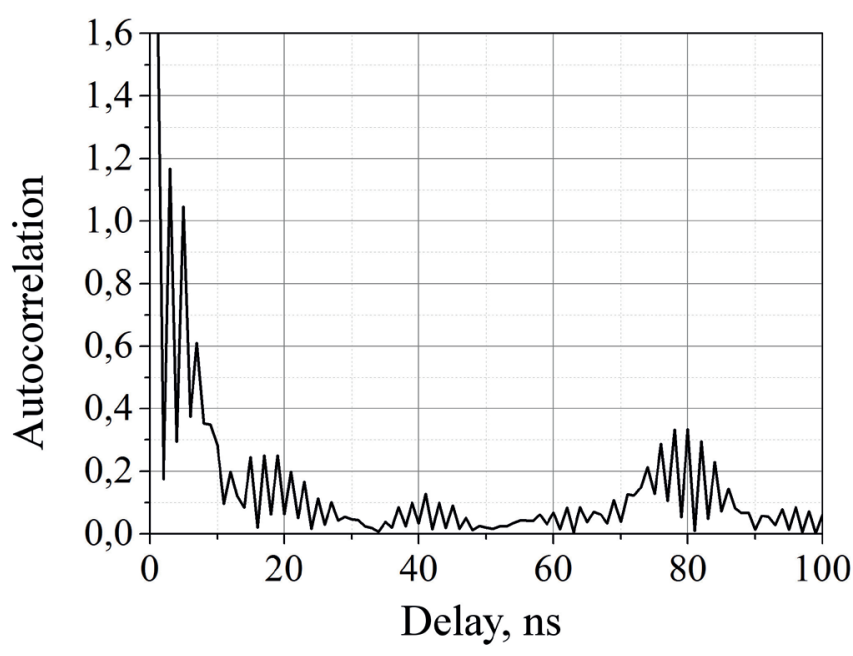

Fig. 17. Autocorrelation function of the "chaotic" signal.

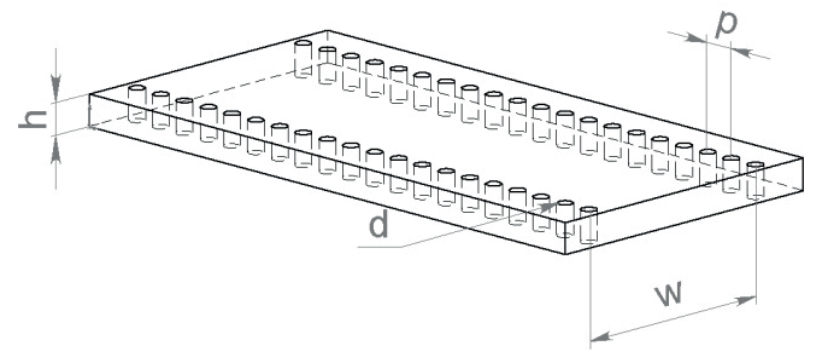

Fig. 18. Substrate integrated waveguide.

substrate bounded by two parallel metal plates and two rows of metal cylindrical passages (holes) providing the equipotential surface. Fig. 18 shows the main parameters of the waveguide integrated into the substrate: $p$ - distance between holes, $d$ - hole diameter, $b$ - thickness of the substrate, $w$-width of the waveguide, $\varepsilon_{\mathrm{r}}$ relative permittivity of the substrate [16].

Attention has been paid to this design last few years due to the increased packing density of the components on the printed circuit boards and the need to reduce the mutual influence of feeder lines. In our case this feed line type is also preferred to simplify the excitation process. By its parameters, this design is close to the rectangular metallic waveguide filled with dielectric, but it also has a frequency selectivity that is typical for periodic structures. Advantage of this technology - the possibility to integrate all components on the single substrate including passive components, active components and antenna [17].

\subsection{DESIGN OF THE ANTENNA- OSCILLATOR, INTEGRATED WITH}
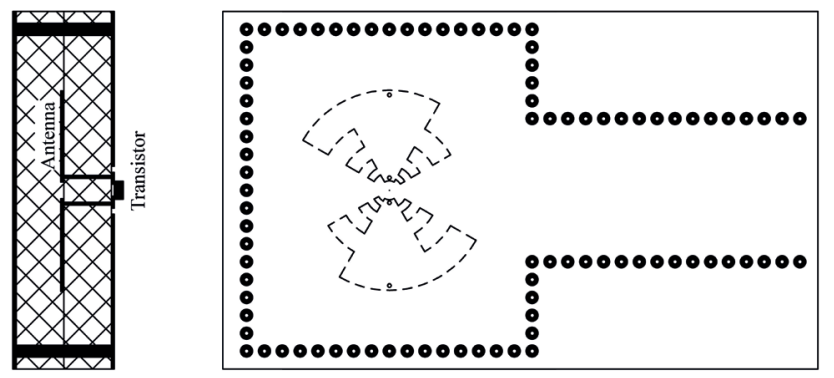

Fig. 19. Design of active antenna integrated with SIW structure. 


\section{SIW}

The following design (Fig. 19) is proposed to evaluate the effectiveness of the abovedescribed active antenna with SIW structure. Log-periodic antenna (transmitter) is located on the one side of dielectric substrate and is integrated into the SIW structure with corresponding characteristics. SIW structure consists of two dielectric substrates with metalized sides and transitional conducting holes. Active device (transistor) is located on the external side of the SIW and conducting wires are connected to the antenna petals.

Thus, the antenna is placed into the closed cavity, which is connected with substrate integrated waveguide.

\subsection{SIMULATION OF THE FIELD DISTRIBUTION IN THE STRUCTURE}

Widespread transmission line matrix (3D-TLM) method was used to carry out the simulation of the field distribution in the structure [18]. From the results of the computer simulation (Fig. 20) it is obvious that significant microwave power at $15 \mathrm{GHz}$ (fundamental waveguide mode) transfers from the cavity into the waveguide.

To evaluate the output power bevel of the dielectric edge was made that allows to decrease the reflection losses in the transfer to

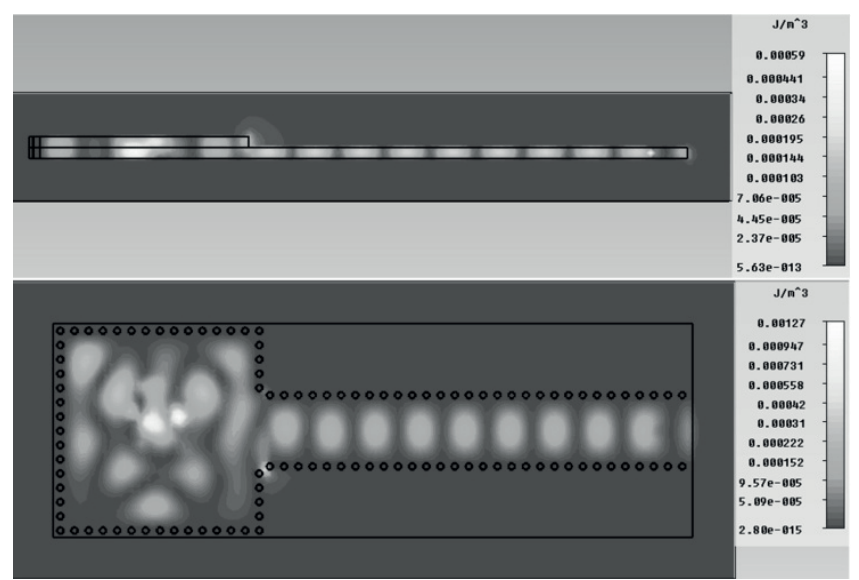

Fig. 20. Distribution of energy in the SIW, integrated with AO. rectangular metallic waveguide. The measured power at the output of the metallic waveguide was about $1 \mathrm{~mW}$, that is comparable with the power, radiated to the free space by the same single antenna-oscillator.

\section{CONCLUSIONS}

1. Microstrip log-periodic antenna integrated with FET is an effective microwave oscillator. There are several oscillation modes: single frequency, multi-frequency and chaotic oscillations. AO is a miniature integrated unit and can be used as a portable microwave source for a wide range of applications.

2. Array of AOs, located on the same substrate, can be mutually synchronized due to the wave interaction via the substrate or with external synchronizing signal.

3. Semitransparent mirror located in front of the AO array increases mutual synchronization bandwidth. As a result the output power increases and radiation pattern narrows.

4. Microstrip antenna-oscillator, integrated with SIW structure, provides an effective radiation output into the dielectric or hollow metal waveguides. So the integration of such structures (including arrays) into the multi-functional radioelectronic units can be performed.

5. Microstrip antenna oscillators can be used as portable sources of microwave radiation particular in medical applications [14]. Of particular interest is to use them in the millimeter wave set up. In this case, due to the small antenna size, they can be manufactured in the form of the monolithic integrated circuits [19]. 


\section{REFERENCES}

1. Lyubchenko VE. Fundamentalnye ogranicheniya i perspektivy primeneniya poluprovodnikovykh priborov $\mathrm{v}$ radiosistemakh millimetrovogo diapazona voln [Fundamental limitations and prospects of application of semiconductor devices in radio systems millimeter wave range]. Radiotekhnika, 2002, 2:16-27 (in Russ.).

2. Chang K, York RA, Hall PS, Itoh T. Active Integrated Antennas. IEEE Trans., 2002, MTT-50(3):937-944.

3. Gupta KC, Hall PS (Eds.). Analysis and Design of Integrated Circuit-Antenna Modules. John Wiley \& Sons, Inc., New YorkToronto, 2000.

4. York RA, Popovich ZB (Eds). Active and Qasi-Optical Arrays for Solid-State Power Combiners. New York, Wiley, 1997.

5. Qian Y, Itoh T. Progress in Active Integrated Antennas and their Application. IEEE Trans.Microwave Theory Tech., 1998, 46:1891-1900.

6. MinkJW. Quasi-Optical Power Combining of Solid-State Millimeter-Wave Sources. IEEE Trans. Microwave Theory Tech., 1986, MTT-34(2):273-279.

7. Lyubchenko VE, Kotov VD, Yunevich EO. Aktivnaya mikropolozkovaya antenna $\mathrm{s}$ diodom Ganna [Active microstrip antenna with a Gunn diode]. Iqv. Vyssh. Uchebn. Zaved., Radiofir, 2003, 46(8-9):799803 (in Russ.).

8. Scheuring A, Wuensch S, Siegel M. A novel analytical model of resonance effects of log-periodic planar antennas. IEEE Transactions on Antennas and Propagation, 2009, 57(11):3482-3488.

9. Lyubchenko VE, Telegin SA, Yunevich EO. Modelirovanie logoperiodicheskoy pechatnoy antenny metodom prostranstvennoy matritsy peredayuschikh liniy [Modeling log-periodic antenna printed by the spatial matrix of transmission lines]. Radiotekhnika, 2013, 4:82-86 (in Russ.).

10. Kalinin VI, Kotov VD, Lyubchenko VE, Yunevich EO. Sinkhronizatsiya i slozhenie moschnostey antenno-svyazannykh tranzistornykh generatorov $\mathrm{v}$ SVCh diapazone [Synchronization and addition of power of the antenna-connected transistor generators in the microwave range]. Proc. 21th Int. Crimian Conf. "Micwave and telecommunication technology», Sevastopol, Ukraina, 12-16 Sept. 2011, pp. 179-180 (in Russ.).

11. Kalinin VI, Kotov VD, Lyubchenko VE, Yunevich EO. Sinkhronizatsiya i slozhenie moschnostey antenno-svyazannykh tranzistornykh generatorov $\mathrm{v}$ SVCh diapazone [Synchronization and addition of power of the antenna-connected transistor generators in the microwave range]. Izv. Vyssh. Uchebn. Zaved., Radiofir, 2011, 54(8-9):1-6 (in Russ.).

12. Kalinin VI, Kotov VD, Lyubchenko VE, Yunevich EO. Sinkhronizatsiya i slozhenie moschnostey izlucheniya mikropolozkovykh antenngeneratorov na polevykh tranzistorakh [Synchronization and addition radiation power of microstrip antennas generators FET. Izv. Vyssh. Uchebn. Zaved., Radiofir, 2011, 54(8-9):684-689 (in Russ.).

13. Lyubchenko VE, Yunevich EO, Kalinin VI, Kotov VD, Radchenko DE, TeleginSA. Generatziya mikrovolnovogo izlucheniya aktivnymi antennami na polevykh tranzistorakh v kvaziopticheskom rezonatore [Generation of microwave radiation by active antennas FET in quasi-optical resonator]. Radiotekhnika $i$ 
14 VLADIMIR E. LYUBCHENKO, EVGENY O. YUNEVICH, VALERY I. KALININ,

Elektronika，2013，58(12):1192-1196 (in Russ.).

14. Betskiy OV, Baranov AD, Kotov VD, Lyubchenko VE, Radchenko DE, Yunevich EO. Generator electromagnitnykh voln SVCh i KVCh diapazona dlya biomeditsinskikh issledovaniy i terapii [Generator of electromagnetic waves of microwave and EHF for biomedical research and therapy]. Patent RF №2012123684 of 07.06.2012, Reg. in Gosreestr 10.01.2013.

15. Murata M, Matsui M, Tanaka M, OhmoriS. Active radiating butterfly antenna. IEEE Antennas and Propagation Society Intern. Symposium Digest, 1997, 4:2464-2467.

16. Donez IV. Elektrodinamicheskiy analiz integrirovannogo v podlozhku volnovoda [Electrodynamic analysis of the integrated into the substrate waveguide]. Electromagnetic waves and Electronics Systems, 2008, 13(5):22-25 (in Russ.).

17. Bozzi M, Georgiadis A, Wu K. Review of Substrate Integrated Waveguide (SIW) Circuits and Antennas. IET Microwaves, Antennas and Propagation, 2011, 5(8):909-92.

18. Christopoulos C. The Transmission-Line Modeling Method TLM. New York, IEEE Press, 1995.

19. Bryantseva TA, Lyubchenko VE, Markov IA, Yunevich EO. Mikropoloskovaya antenna na arsenide galliya [Microstrip antenna gallium arsenide]. Patent RF №128788 of 27.05.2013, Reg. in Gosreestr 27.05.2013. 